\title{
Energiewende and competition in Germany: diagnosing market power in wholesale electricity market
}

\author{
Thao PHAM ${ }^{1}$
}

\begin{abstract}
German power market has undergone many fundamental changes in 2011 following the Fukushima nuclear accident (March 2011). Prices on wholesale electricity market are at the highest level since mid-2009. The purpose of this chapter is to identify whether market power is responsible for this increase. Following the method of linear programming as commonly used in the literature of electricity market modelling, we simulate a competitive benchmark for German wholesale market taking into account power plant characteristics, fuel and CO2-allowance prices and renewables power generation. On the basis of the difference between modeled marginal costs and observed market prices, we estimate the price-cost markups, or the Lerner Indexes across hours.
\end{abstract}

Keywords: Electricity, market power, Germany, oligopolistic market.

${ }^{1}$ LEDa-CGEMP University of Paris Dauphine, email: thi-phuong.pham@dauphine.fr

I would like to thank Marie Bessec, Jacques Percebois, Michel Cruciani and Sophie Meritet for their helpful comments and suggestions. All remaining errors are my own. 


\section{Introduction}

The electricity reform was put in place around Europe for more than two decades and in reality, the design of these newly-opened markets has not been yet definitive. Some important problems are still unsolved, one of them concerns "market power".

"Market power" is not a new concept. It is defined in economics as the ability to alter profitably prices away from competitive level, i.e , the marginal cost level. Theoretical and empirical studies of "market power in electricity markets" however, have only been developed recently. It raises concerns in both sides of the Atlantic, as regard to the way of defining, detecting, and monitoring it. Up to the late 1980s, empirical studies of market power in liberalized generation electricity markets were scarce since it had rarely been contemplated outside the United States (Borenstein [2000]). Studies in Europe were developed a bit latter but most of them had attempted to assess the potential for exercising market power by measuring the extent of market concentration in regional submarkets. Over the last 10 years, market power studies have been carrying out in many electricity markets and detection techniques have also dynamically evolved.

In Germany, the empirical studies on the performance of wholesale electricity market have been much employed. The country has followed the model of vertically integrated oligopoly where four dominant firms controlled over 90\% of market share by the beginning of 2001 and approximately $77 \%$ at the end of 2011 according to the Federal Cartel Offices monitoring data. From 2001 to 2008, electricity prices were more than triple in the wholesale market in Germany, soaring from about 25 to $87 € / \mathrm{MWh}$. This had drawn increasing attention from both academics and regulators to investigate the exercise of market power in the German market during this period. See for example, Bower, Bunn and Wattendrup [2001], Möst and Genoese [2009] using an agent-based simulation model or Lang and Schwarz [2006], Müsgens [2006], Weigt and Von Hirschhausen [2008] using a linear optimization programming. Though each paper takes different approaches and uses different modelling methods, they essentially come up with similar conclusions about the existence of market power abuse in 2006, when wholesale electricity prices experienced an exceptional increase in Europe especially in Germany. Since then, the German electricity market has undergone significant changes, yet the discussion about the appropriate market design and market regulation seems not come to an end.

Shortly after the global economic crisis hit the energy-fuels markets, German wholesale electricity prices dropped sharply but began to rise rapidly, on average from $37 € / \mathrm{MWh}$ in 2009 to 51 $€ / M W h$ in 2011 (37\%) before slightly decreasing again in 2012 (according to the data from EEX). At the same period, oil prices started to surge, exceeding $\$ 100 /$ barrel in 2011. Although a price increase does not necessarily imply an abuse of market power, the oligopolistic structure of Germany's generation market has brought forward some doubts about the malfunctioning of the market.

In this paper, we investigate the level of competition in German wholesale electricity market in 2011, when market spot prices in Germany experienced a significant increase since 2009 and 
many changes in German energy policy were implemented following the Fukushima's nuclear accident in March 2011. Following the method of linear programming as commonly used in the literature on electricity market modeling, we simulate a competitive benchmark for German wholesale market as done by Müsgens [2006] and Weigt and Von Hirschhausen [2008]. We take into account plant characteristics, fuel and CO2-allowance prices and renewables power generation. On the basis of the difference between modeled marginal costs and observed market prices, we estimate the price-cost markups, or the Lerner Indexes across hours.

The paper proceeds as follows. The first section discusses the market design and recent evolution of electricity market in Germany. We provide also a literature review of relevant studies analysing market power in the German spot market. A general overview of linear programming model description as well as the data are given in Section 2. We conduct several robustness checks and summarize our main findings as well as the economic interpretation of the model-based results in the Section 3. The last section concludes.

\section{Literature review on market power in German electricity spot market}

We describe in this section the fundamental factors and recent evolutions in German power system in the context of energy transition in this country. We then provide a literature review of quantitative studies on market power issue in the Geman wholesale electricity market.

\subsection{Germany's wholesale electricity market}

The German electricity market is the largest in Europe, with annual power consumption of around $600 \mathrm{TWh}$ and an installed generation capacity of $171.7 \mathrm{GW}$ (data in 2011 according to OECD/IEA [2013]). German electricity market was liberalized in 1998 following the 1996 EU Electricity Market Directive. The Energy Industry Act (Energiewirtschaftsgesetv) came into force, ending more than 100 years of local monopoly and opening the electricity market fully to competition with a minimum of institutional interference ${ }^{2}$. As a result of intense competition, wholesale electricity prices fell by as much as 60\% (Atkins and Taylor [1999]). In response to the significant fall of prices and profits, all eight of the major vertically integrated electricity companies, and many other smaller ones, were involved in a merger and acquisition process (Bower et al. [2001]). The German electricity market was thus transformed from a fragmented highly competitive market structure at the beginning of 1999 to a vertically integrated oligopoly one where four dominant firms controlled over $90 \%$ of market share by the beginning of 2001 . In 2011, four largest utilities - E.ON, RWE, EnBW and Vattenfall Europe supply approximately

\footnotetext{
2 At time of liberalisation, there were neither independent system operator nor transmission regulators in Germany. The questions of grid access and transmission pricing were left to be negotiated among different electricity companies and the German heavy industries.
} 
$77 \%$ of the market according to the Federal Cartel Office's monitoring data ${ }^{3}$. This market structure continues to evolve in response to many recent changes in the European energy market.

Over the last decade, the European electric power sector has experienced an exceptional policy trend that fundamentally reshaped the industry: the intrusion of environmental-related policies. Germany is perhaps the most distinguished example of this energy policy trend. One day after the nuclear catastrophe in Fukushima in March 2011, the German government decided, with the support of quasi-totality of German population, to accelerate the phase-out of nuclear fleet by 2022 - a policy which had been discussed since the beginning of 2000. It starts with the immediate closure of the eight oldest nuclear plants, and to continue to expand renewable energy capacity (Energiewende).

Figure 1: Electricity production in Germany - 2011

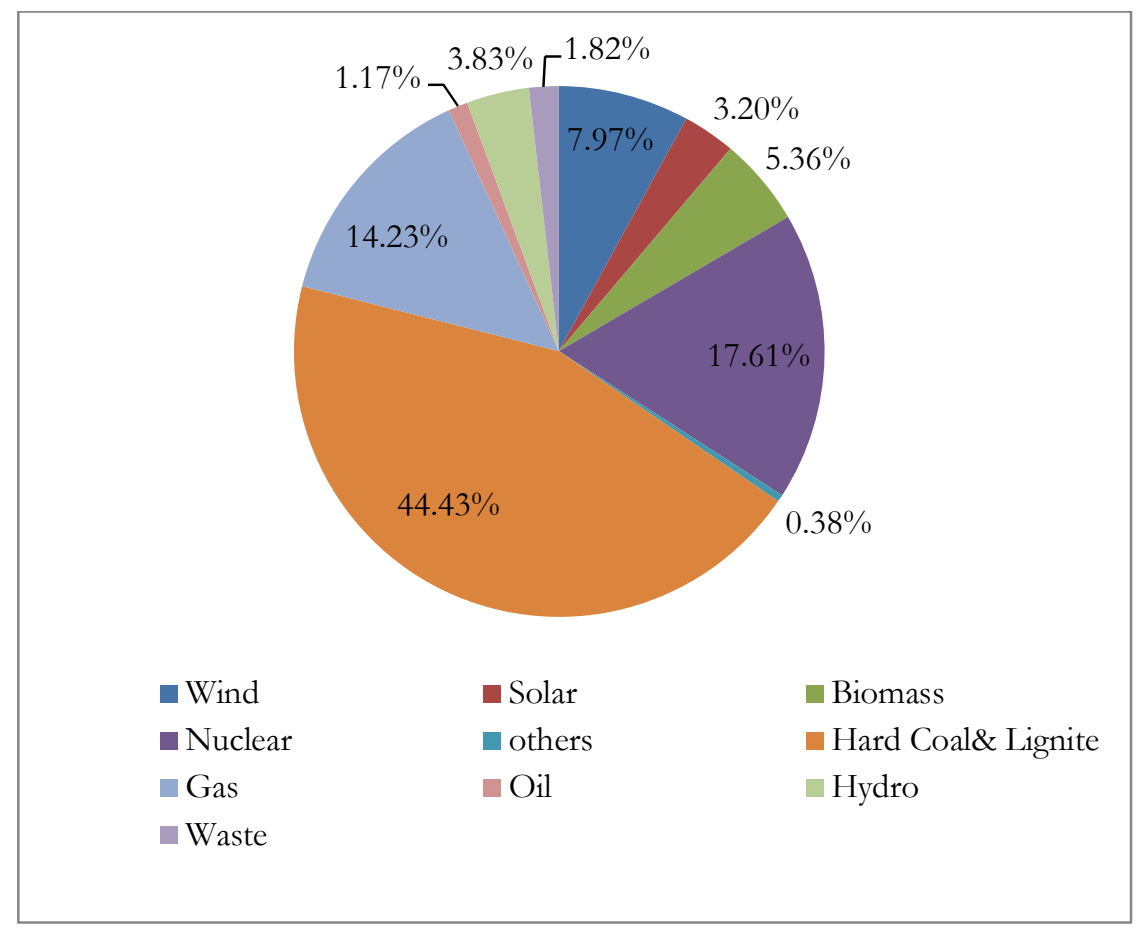

Source: IEA (2014)

In 2011, wind, hydro and solar supplied together around 15\% of electricity balance in Germany and this share should increase to $35 \%$ by 2020 and $80 \%$ by 2050 . Hard coal and lignite are still

\footnotetext{
${ }^{3}$ Under the Energy Act (EnWG) and the Competition Act (GWB) respectively, the Bundesnetzagentur (German regulatory authority) and the Bundeskartellamt (Federal Cartel Office) were required to conduct a joint Monitoring Report on activities in the electricity and gas sectors in 2012.

4 The Energy Concept (Energiewende) was adopted by the federal government in September 2010 to set out the Germany's energy policy until 2050. The role of nuclear power in the (Energiewende) was reassessed following the Fukushima nuclear disaster in March 2011. The federal government decided, with the support of the majority of German population, to immediately shut down the eight oldest nuclear power plants and the remaining nine nuclear power plants on a phased basis by 2022. Although fossil fuels fired energy has to put in place during the transitional period, renewable electricity generation is being considered as cornerstone of current and future energy supply.
} 
comprised about $45 \%$ of the total production in 2011 (Figure 1). The shutdown of eight nuclear plants with a combined capacity of about $8.4 \mathrm{GW}$ has reduced the electricity production from this type of energy from around 140556 GWh (22.5\%) in 2010 to 107971 GWh (18\%) in 2011. This closure has also reduced the market share of the big four generators. Nonetheless, they still account for about 73\% of generating capacity according to the Monitoring Report 2013, Developments of the Electricity and Gas Markets in Germany, Federal Network Agency and Federal Cartel Office, 2013 (FNA and FCO [2013]). Given the large amount of available interconnection capacity between Austria and Germany, these two markets are considered to comprise one electricity market, diluting the market share of the big four by approximately $10 \%$.

As regards electricity wholesale prices, there was a significant increase in German spot market in 2011, compared with the previous years (2009 and 2010): from 37€/MWh in 2009 to $51 € / M W h$ in $2011(37 \%)$ on average before a slight decrease in 2012 (figure 2).

Figure 2: Evolution of Germany's daily spot price 2009-2013

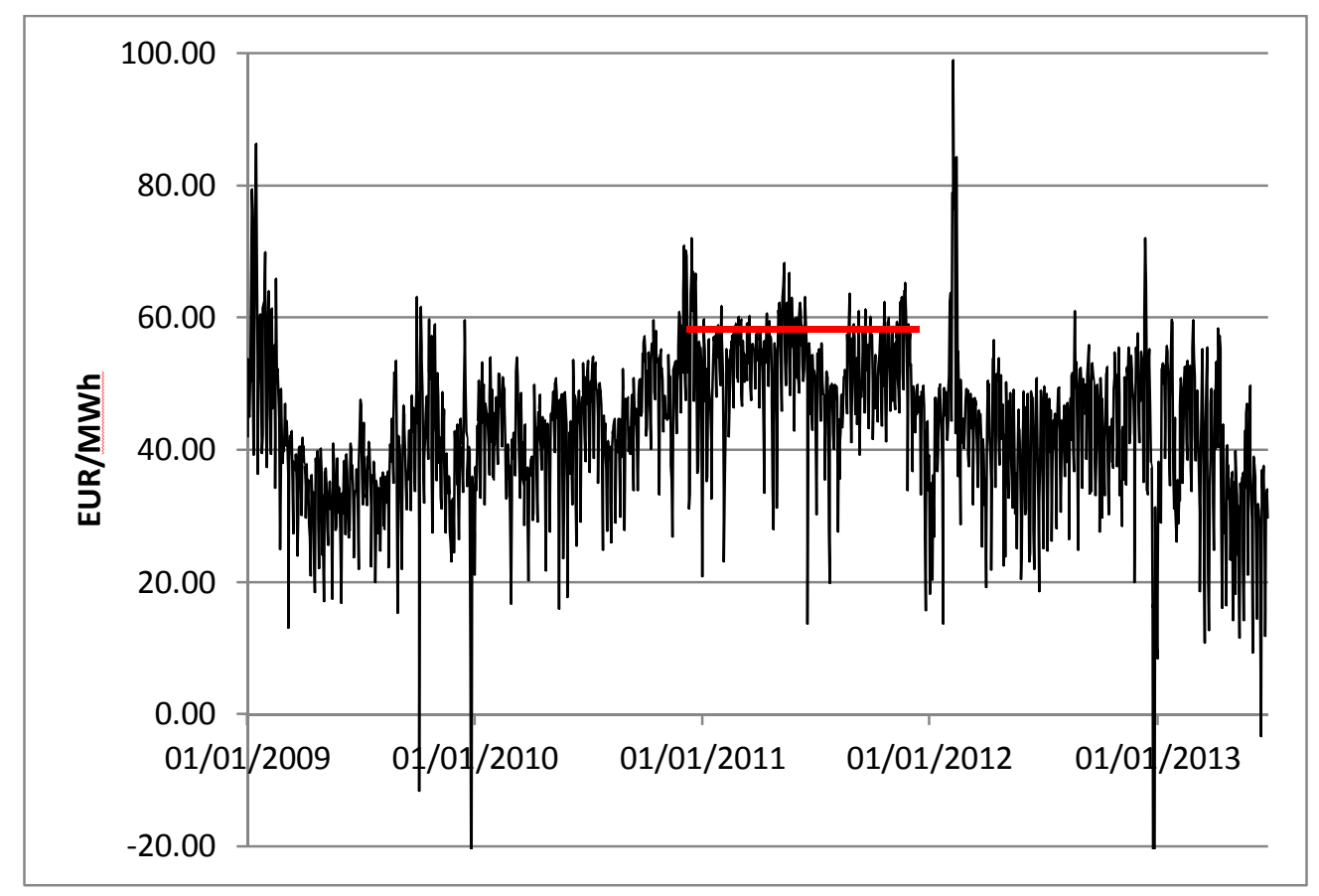

Source: EPEX Spot

It is difficult to conclude about the nature of the increase in spot prices during this period without a quantitative analysis. In fact, the Energiewende policy of replacing nuclear power with extra fossil fuel capacity and vastly expanding highly-subsidized renewables has two different impacts in wholesale power prices. On the one hand, the extra fossil fuels generation was supposed to increase the wholesale spot prices due to its expensive fuel costs. In the other hand, the massive integration of renewable power generation (from wind, solar, biomass) should drive the electricity spot prices down because electricity produced from renewable is bidded at zero 
price on the market, following the Feed-in-tariff mechanism ${ }^{5}$ - the so-called "the merit order effect".

To sum up, the Energiewende policy could induce two different impacts on the wholesale market prices. While the substitution of nuclear power by extra fossil fuels capacity would increase the electricity spot prices, the vastly expanding highly-subsidized renewables would lower the spot prices, even to a negative level ${ }^{6}$. The nature of high prices observed in 2011 is thus difficult to justify. Given the oligopolistic structure of Germany's generation market, the question of whether the market outcomes represent competitive behavior has been brought forward.

\subsection{Literature on market power in Germany's wholesale market}

The quantitative studies on market power in Germany's wholesale electricity market have been often employed in literature particularly in the period 2000-2008. After a few years since the European liberalization process, wholesale electricity prices have increased dramatically in Germany even though there was a sharp fall in prices at the beginning of the liberalization. Within a couple of years, the disappearance of more than one-third of small companies after the M\&A negotiations and the dominance of four big utilities brought about the same regulatory dilemma as many other countries that have liberalized their electricity markets: how to control the abuse of market power in a highly concentrated oligopoly structure. This had drawn much attention from both academics and regulators to investigate the exercise of market power in the German market during this period. Most of the studies used simulation market models to estimate the marginal costs. On the basis of the difference between the estimated costs and observed market clearing prices, the authors conclude about the competitiveness of the outcomes (For more details on various techniques to detect market power in a given electricity market, see Meritet and Pham [2015] or Twomey, Green, Neuhoff and Newbery [2006]).

The earliest study investigating market power abuse in the German electricity market was carried out by Bower et al. [2001]. Using an agent-based simulation model in 1998, the authors showed that the process of strategic consolidation with the creation of four dominant firms in the early years of liberalization led to a substantial increase in market power in the wholesale electricity market and hence to a significant rise in price-cost markups during this period. Using the same

\footnotetext{
5 The Energiewende has; however, increased the regulated tariffs paid by the final consumers due to the heavily subsidized renewables integrated massively into the electricity system during recent years. It is important to note that German retail prices of electricity are at the highest level in Europe except those of Denmark - European champion for $\mathrm{CO} 2$ emissions and the development of wind power. The cost of subvention for renewable generators made retail prices even higher. This amount is expected to increase from $5.3 \mathrm{ct} / \mathrm{kWh}$ in 2013 (20\% of total 2013 price) to around $6.2 \mathrm{ct} / \mathrm{MWh}$ in 2014 according to Eurostat data.

${ }^{6}$ Negative prices are the consequence of two coincident events: a low demand and a very high level of wind which makes off-shore wind turbines in the Baltic run at full speed. When this situation occurs, the conventional thermal plants are required to back down so that demand and supply can be in balance. Some conventional generators, however, wish to continue to run because shutting down their plants would cost them too expensive knowing that they have to restart them a few hours afterwards (technically, it is not that simple). In this case, they prefer to pay an operator who could accept to take the electricity that they inject into the network rather than shut down their plants and suffer the startup costs. It would be the Swiss generators, who dispose a high capacity of pumped storage hydroelectricity and who would be paid for evacuating this excess electricity. This is the nature of "negative prices" issue (See more details in Benhmad and Percebois [2013]).
} 
approach of agent-based simulation model, Möst and Genoese [2009] carried out the analysis for 2001, 2004, 2005 and 2006 in Germany. They concluded that the exercise of market power could not be verified.

Müsgens [2006] estimated the degree of market power in German wholesale electricity market for the period of June 2000 - June 2003. Using a linear optimization model, he simulated the competitive benchmark of market prices to reveal the level of market power. Müsgens concluded that until August 2001, the observed market prices were based on competitive marginal costs. From September 2001 onward; however, a divergence as large as 50\% to 77\% between the observed and modeled market prices was found. He regarded this as strong evidence of market power and that strategic company behavior and learning effects were the main drivers. Using a similar approach, Lang and Schwarz [2006] conducted an investigation of market power in German wholesale electricity market during the period from June 2000 to December 2005. The authors took into account the $\mathrm{CO} 2$ prices in estimating marginal costs. In line with Müsgens [2006], they found that no market power was exercised in 2000 and 2001 as observed prices were rather close to the modeled ones. From 2002 onward, there was a substantial deviation of market prices to the competitive benchmark, varying from 30\% in 2003 and $15 \%$ in 2004 and 2005 particularly in peak hours. However, the authors concluded that apart from peak times in 2003, the increase of prices due to market power was considered to be small. The price rise in this period was rather traced back to the high fuel prices and the additional cost of CO2 allowances. Weigt and Von Hirschhausen [2008] followed Lang and Schwarz [2006] and extended the analysis to 2006. They found that market prices were above competitive levels for a significant period of time in 2006. Facing a significant rise of electricity prices in Europe, the European Commission launched an in-depth analysis Competition [2007] using various approaches (concentration indexes such as CR, HHI, PSI, RSI and linear optimization model). The final report confirmed that the German wholesale electricity market undergone markups of $50 \%$ from 2003 to 2005.

Janssen and Wobben [2009] took a different approach. Instead of relying on an estimate of the entire generation cost, they investigate producers' behaviors in the context of electricity pricing with respect to several time-dependent marginal costs (TMCs). The authors derive the work-on rates, which provide information about the impact of TMC variations on electricity prices in different market structures: perfect competition, quasi-monopoly and monopoly. Comparing these model-based work-on rates with actual work-on rates, which are estimated by an adjusted first-differences regression model of German power prices on fuel costs and emission allowances, the authors find the evidence of the exercise of market power in the period 2006 to 2008.

More recently, Schill and Kemfert [2011] develop a game-theoretic computational Cournot model to analyze strategic electricity storage utilization in an imperfect market setting. They apply the model to the German electricity market using reference demands and prices of a particular week in October 2008. The authors conclude that introducing pumped storage smoothes market prices and increases consumer rent and overall welfare. 
Though each author incorporates different assumptions in their models, most papers cited above apply a similar approach to estimate the level of market power. On the basis of the difference between modeled marginal costs and observed market prices, the authors calculate the mark-up costs and they essentially come up with similar conclusions. The general suggestion in all of those papers is that there has been evidence of market power abuse in the German electricity wholesale market during the period 2005-2008. However, it is important to note that estimating a costproxy is extremely challenging. As mentioned in section 2.3.2, the lack of full information in the empirical model could weaken the conclusion. As Harvey and Hogan [2002] demonstrate, every model has some level of uncertainty and thus produces a range of possible outcomes. We are fully aware of this criticism as interpreting the mark-up results in this paper.

\section{Model and data}

This section describes the approach of competitive benchmark analysis that is commonly used in most papers and the data. We follow the method of linear programming model in Müsgens [2006] and Weigt and Von Hirschhausen [2008] to simulate the German wholesale market in which all demand is cleared via a single market process. The modeled market clearing prices are subject to be compared with the observed EPEX German market prices. In fact, the electricity traded via EPEX platform comprises only about 30\% of total consumption. As this is the only publicly available source, we assume that EPEX spot prices act as benchmark for OTC trading or forward market prices.

\subsection{Model formulation}

The power system consists of a set of nodes = $\quad \ldots$, at each of which there is the demand and deterministic injection of three kinds of renewables: wind, solar and biomass - generation

, , . The power generation from these renewables sources are injected to the system independently from the market conditions and priced at zero following the feed-in tarif mechanism. The residual demand is then served by dispatchable plants $=\ldots$, each of which being located at a certain node. Each conventional plant exhibits constant marginal generation costs and a maximum capacity . Exports to or imports from neighboring countries are taken into account implicitly by adjusting the demand data (see Section 3.2). The market clearing prices are determined at the same level across all nodes. Perfect competition is assumed to find a competitive benchmark.

In a perfect competition situation, the hourly electricity spot prices reflect the short-run marginal cost of the most expensive technology amidst all the plants mobilized to satisfy the hourly demand. The system prices are thus determined by a traditional optimization program which minimizes the costs of meeting the hourly demand subject to the energy balance and the capacity constraint. To ease the non-linear calculation burdens, start-up/shut-down costs, ramp up and down rates are not taken into account (See Weigt and Von Hirschhausen [2008] about the startup constraints). In the following, variables are denoted by capital letters, parameters are denoted by lowercase letters. 


$$
=\Sigma,(, \quad) \text { Objective }
$$

where, are the marginal generation costs of plant $p$ in hour $t$, and, is the dispatched output of that plant in hour $\mathrm{t}$. The output of a plant is restricted by the thermal capabilities of the generation process:

$$
\leq \quad \text { Capacity constraint }
$$

with and as the minimum and maximum available power output. The maximum generation is calculated based on the availability rate for each technology $i$ and generation capacity of each plant $p$ and the minimum generation is calculated based on the minimum generation rates associated to each technology and the generation capacity of each plant:

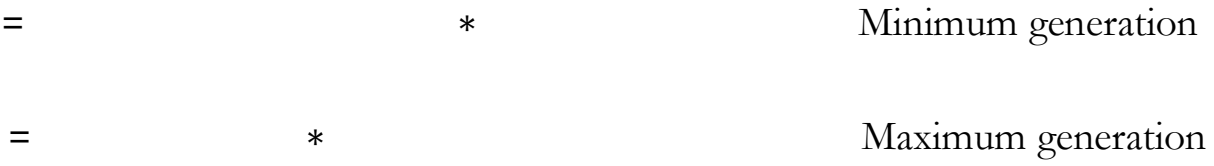

The marginal generation costs, of plant $p$ in hour $t$ consist of the fuel costs based on plant efficiency and fuel price , operating costs, and opportunity costs for emissions based on plant-specific $\mathrm{CO} 2$ emissions and the associated CO2 price (on daily basis) at the EEX.

$$
\text { , }=-++\quad+\quad+\quad \text { Marginal costs of generation }
$$

As the model is ex-post analysis, demand $\mathrm{d}$ in hour $\mathrm{t}$ is known and has to satisfy the supplydemand balance:

$$
=\sum, \quad+\quad+\quad+\quad \text { Energy balance }
$$

with , , are power generation from wind, solar and biomass respectively in hour t. Network constraints are not considered and thus losses are not taken into account.

The Lagrange multipliers or shadow prices associated to the supply-demand balance constraints indicate the marginal values and therefore the prices for the next incremental load $\lambda=$ $\frac{(,)}{(,)}$

\subsection{Data}

The application of the described model covers the electricity system of Germany for the year 2011. In the following, we present the data sources as well as the assumptions on generation and load. Most of the data described below is taken from the data documentation of Deutsches 
Institut fur Wirtschaftsforschung done by Schroder, Kunz, Meiss, Mendelevitch and Von Hirschhausen [2013].

\section{Generation}

As described above, we explicitly distinguish between conventional thermal generation and renewable power generation. The former is indeed subject to be dispatched at specified marginal generation costs determined by (5) and the latter is neither dispatchable nor subject to any uncertainty, but enters the model as deterministic data.

Thermal generation is considered on block level, and capacities as well as locations of plants are based on BNetzA [2014]. We take into account the post-Fukushima impacts on nuclear power generation by adjusting generation capacity with the shutdown of 8 nuclear plants from midMarch 2011 (total capacity of around 8.5 GW).

The information used to estimate the marginal generation costs about input fuel for nuclear, lignite, hard coal, gas, oil, hydro and technologies such as steam process, gas turbine, combined cycle gas turbine as well as the data/assumptions on fuel prices, carbon content, is summarized in table 1 .

Table 1: Information on different technologies and fuels

\begin{tabular}{rrrrrrr} 
Technology & Main Fuel Efficiency & $\begin{array}{r}\text { Price } \\
\boldsymbol{E} / \mathbf{M W h}\end{array}$ & $\begin{array}{r}\text { Carbon } \\
\text { Content } \\
\text { t/MWh }\end{array}$ & $\begin{array}{r}\text { Availability } \\
\mathbf{\%}\end{array}$ & $\begin{array}{r}\text { Min } \\
\text { Generation }\end{array}$ \\
Nuclear & Uran & $31 \%$ & 3 & 0 & $90 \%$ & $45.16 \%$ \\
Lignite & Lignite & $37 \%$ & 4 & 0.364 & $90 \%$ & $40 \%$ \\
Coal & Hard Coal & $42 \%$ & 13.143 & 0.354 & $90 \%$ & $38 \%$ \\
CCGT & Gas & $54 \%$ & 29.603 & 0.202 & $91 \%$ & $33 \%$ \\
OCGT & Gas & $34 \%$ & 29.603 & 0.202 & $90 \%$ & $20 \%$ \\
Gas Steam & Gas & $39 \%$ & 29.603 & 0.202 & $90 \%$ & $38 \%$ \\
CCOT & Oil & $50 \%$ & 43.606 & 0.279 & $91 \%$ & $33 \%$ \\
OCOT & Oil & $34 \%$ & 43.606 & 0.279 & $90 \%$ & $20 \%$ \\
Oil Steam & Oil & $39 \%$ & 43.606 & 0.279 & $90 \%$ & $38 \%$ \\
Reservoir & Hydro & $100 \%$ & 0 & 0 & $50 \%$ & $0 \%$ \\
PSP & Hydro & $75 \%$ & 0 & 0 & $100 \%$ & $0 \%$ \\
RoR & Hydro & $100 \%$ & 0 & 0 & $50 \%$ & $0 \%$ \\
Wind & & & & & & \\
Onshore & Wind & $100 \%$ & 0 & 0 & $100 \%$ & $0 \%$ \\
Wind & & & & & & \\
Offshore & Wind & $100 \%$ & 0 & 0 & $100 \%$ & $0 \%$ \\
Solar & Sun & $100 \%$ & 0 & 0 & $100 \%$ & $0 \%$ \\
Biomass & Biomass & $42 \%$ & 0 & 0 & $90 \%$ & $38 \%$ \\
\hline
\end{tabular}

Source: Statistik der Kohlenwirtschaft [2013], Schröder et al. [2013], Kunz and Zerrahn [2013] and EEX [2011] 
The data for fuel prices of hard coal, gas and oil is based on Statistik der Kohlenwirtschaft [2013] summarized in Schröder et al. [2013], varying from 13.14€/MWh for hard coal; 29.6€/MWh for gas and 43.6€/MWh for oil. The fuel prices for uranium and lignite are 3 and $4 € / M W h$ respectively, based on the assumptions done by Kunz and Zerrahn. We take the average allowance price in 2011 at the European Energy Exchange (EEX) for simplicity, which yields $12.94 €$ per ton of CO2. The efficiency of the generation process is taken from Kunz and Zerrahn [2013], which is based on the process itself as well as the commissioning year of individual power plants. It ranges from 31\% for nuclear power plant to 54\% for a CCGT plant. An error term is imposed in the range of $0-0.01 \%$. to avoid an underestimation of simulated prices, except for wind, solar and pumped-storage hydro power units, all plants are assumed to have the availability rate at $90 \%$ because a plant can be offline due to various exogenous reasons like weather conditions, maintenance, or outages.

The renewable sources (except hydro) in-dispatchable comprise wind, solar and biomass. The data of wind and solar generation in quarter-hour in 2011 is collected from different TSOs (Tennet TSO, 50 Hertz, Amprion, EnBW) and via EEX for validation. We take the average of four quarter-hours to get the hourly data. Concerning biomass facilities, we assume constant generation at available capacity as done in Kunz and Zerrahn [2013]. The total generation capacity is about $99.8 \mathrm{GW}$ with over 500 power plants including renewable energy sources.

\section{Load}

The data on load is collected from ENTSO-E for 2011. The hourly demand level for Germany ranges between $80 \mathrm{GW}$ at peak (during winter months) and $45 \mathrm{GW}$ at off-peak times. It is important to note that the load data from ENTSO-E refers to the 24 hourly power consumed by the German network including the network losses but excluding the consumption for pumped storage. Furthermore, beside domestic load, part of the available generation capacity could be sold abroad and cannot be used to cover the German demand. For these reasons, the exports to neighboring countries and pumping must be taken into account. We adjust the load data from ENTSO-E with the data from the four German TSOs by including exports and pumping. Table 2 depicts the final demand on a yearly basis.

Table 2: Load and renewable generation in 2011 (in TWh)

\begin{tabular}{rr}
\hline \hline Load incl.exports and pumping & 542.84 \\
Total RES. Generation & 94.70 \\
\hline of which Wind & 44.25 \\
of which Solar & 18.53 \\
of which Biomass & 31.92 \\
\hline
\end{tabular}

Source: EEX, ENTSO-E

\section{Results and sensitivity analysis}


In this section, we compare the model-based market prices with observed priced at the EEX for all hours of 2011, obtaining mark-ups (or Lerner Indexes). Then we check the robustness of the results with several tests. First, to avoid the overestimate of available capacity of power plants, we reduce the availability rate. Because electricity spot prices exhibit a very strong seasonality, we conduct separately four model runs, one for each season with the adjusted seasonal availability factors for each plant type (the highest level of availability in winter months). Second, the modeled prices might be subject to be underestimated due to possibly low fuel prices. Hence, we assess whether an increase in gas and oil prices change the results.

\subsection{Market power and price-cost markups}

The simulated dispatched generation outputs of thermal plants, , are illustrated in figures 7 (annual) and 8 (hourly) in the Appendix. As demonstrated in both figures, hard coal and lignite plants tend to be called most of the time during the examined period: even in the off-peak time, lignite plants took the major share in the electricity mix. The marginal production costs of these plants thus determine the market prices for the majority of time. The shutdown of 8 nuclear reactors since March 2011 (taken into account in the model from 01 April 2011) had a clear impact on the hourly generation output dispatched as shown in figure 8 . The accumulated generation output for 2011 is also presented by the merit order as illustrated in figure 9 in the Appendix.

Figure 3: Comparison of modeled price and EEX.

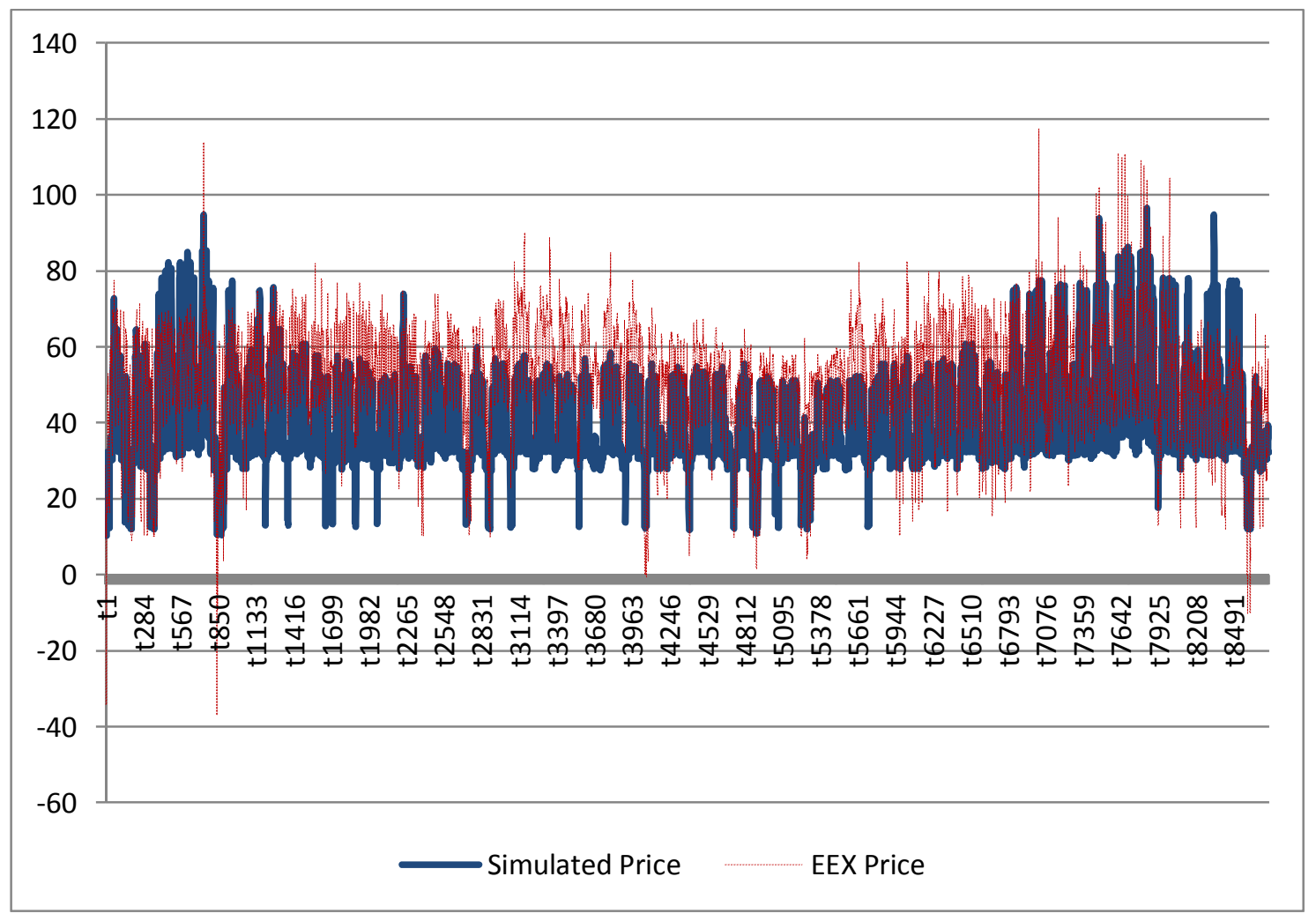

Source: Own calculations and EPEX Spot 
The simulated prices for 8760 hours in 2011 are depicted in figure 3. It is important to note that the simulated marginal costs could be much higher than the observed EEX prices especially during off-peak times because the EEX prices could drop to the very low level, even zero or negative level whereas simulated prices always reach a positive level, representing coal and lignitefired base load plants. Figures 7, 8 and 9 show that lignite and coal plants dominate the production balance of Germany in 2011. In general, prices below marginal costs are explained by startup conditions since the temporary shut-down of a base load plant can become more expensive than maintaining operations without revenues (Weigt and Von Hirschhausen [2008]). The operators thus prefer to bid a price lower than the marginal production costs of their base load plants than shutting them down. The start-up costs are also the reason explaining why market prices could go down to negative levels as described in section 1.1. Figure 3 shows the modeled prices and the EEX prices in the chronological order while figure 4 depicts the modeled prices and the observed prices ordered from highest to lowest EEX price.

Figure 4: Price duration curves: modeled and EEX.

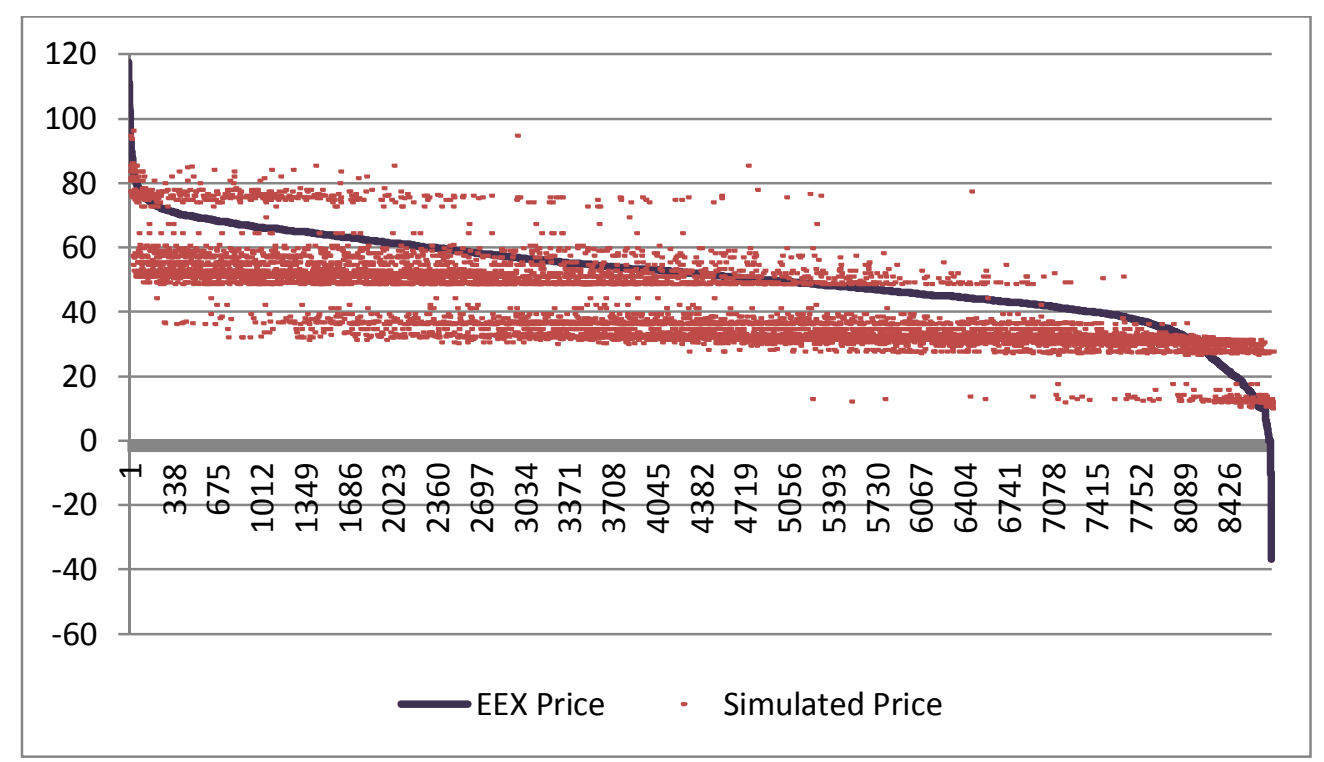

Source: Own calculations and EPEX Spot

The modeled prices are generally below the observed prices. In the off-peak time, both EEX and modeled prices vary between 15 and $40 € / M W h$. The EEX prices; however, dropped toward zero or even negative (effect of subsidized intermittent renewables as described in section 1.1) while modeled prices tend towards a coal and lignite plants. In the mid-price segment the EEX prices range from 40 to $60 € / \mathrm{MWh}$ while the modeled prices range between 30 and $60 € / \mathrm{MWh}$ and generally below the EEX prices. The divergence is also found in the peak load period: the EEX prices increase from 65 to over $100 € / \mathrm{MWh}$ while modeled prices remain between 60 and $80 € /$ MWh.

Figure 5: Lerner indexes across hours 


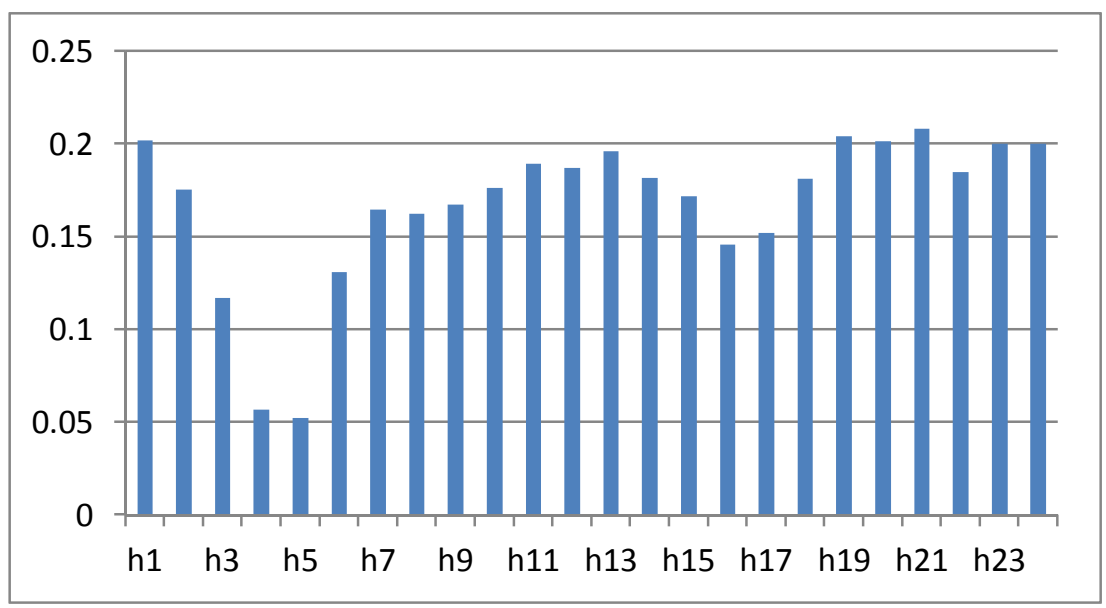

Source: Own calculations

The Lerner indexes are then calculated based on the simulated competitive marginal costs and observed EPEX Spot. The average value is found at $17 \%$ for the year of $2011^{7}$. The hourly average values of Lerner indexes are depicted in figure 5.

\subsection{Robustness tests}

Before coming to the conclusion about the level of market power in 2011, it is essential to conduct several robustness tests. As precised above, all simulation models are subject to a certain extent to errors due to simplifications and assumptions restrictions. The results of these models should be interpreted with carefully.

Hence, we implement two sensitivity tests in this section. First, we alter the availability of power plants. Indeed, the reduction of availability rate of base-load plants would lead to an increase of prices because more peak-load plants would have to be mobilized to satisfy the demand. We model separately the four seasons in the year with different power plant availability for each season. On average, we reduce the availability by $3 \%, 4 \%, 5 \%$ and $6 \%$ in winter, spring, fall and summer months. Due to a lack of information, we could not take into account other important factors that affect the availability rate of power plants as hourly weather conditions, hourly water level or plant outages, etc. Second, we vary the fuel price level by increasing prices for oil and gas by $10 \%$. In fact, the uncertainty of fuel prices could lead to underestimate the marginal costs. Higher oil and gas prices should lead to an increase in peak prices when CCGT and oil or gas fired steam plants set the market price.

The results are shown in the figure 6, which demonstrates the price duration curves of three model sets: the basic case and the two sensitivity-testing cases.

Figure 6. Price duration curves

\footnotetext{
${ }^{7}$ Several extreme values of EPEX prices (both negative and positive) are removed to keep the standard deviation at normal levels.
} 


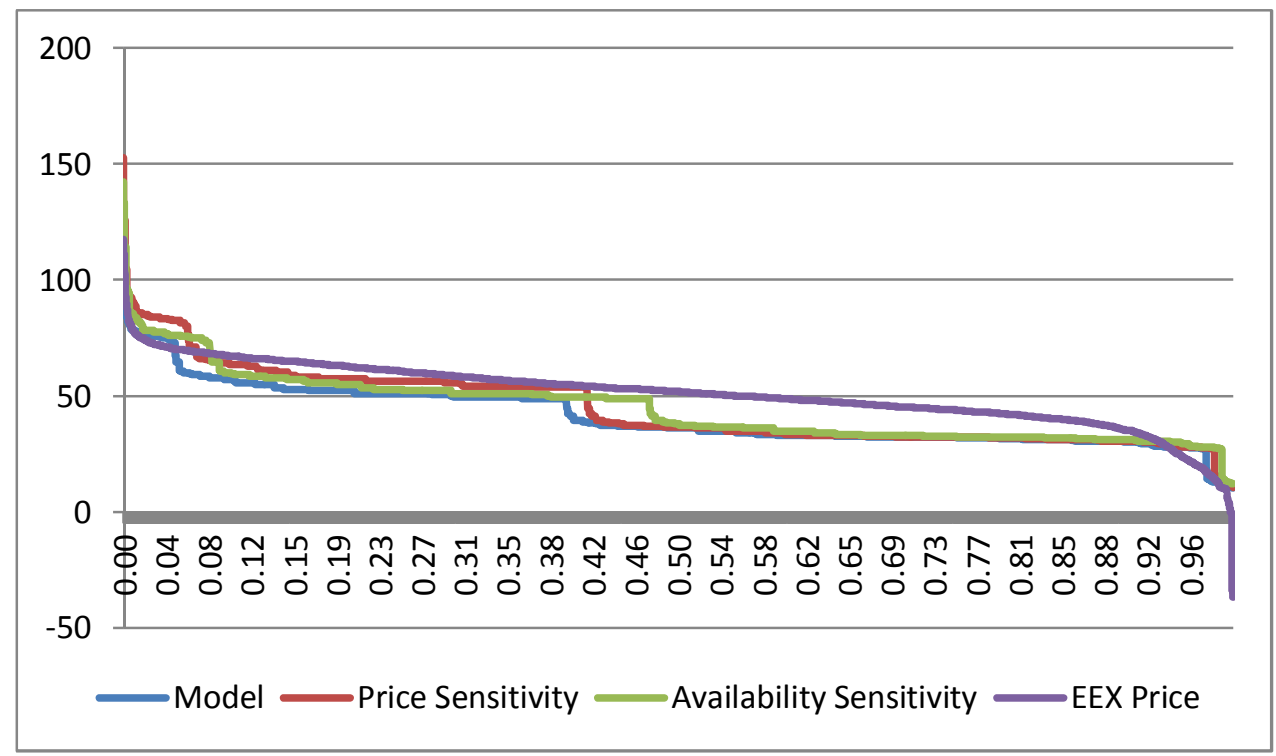

Source: Own calculations and EPEX Spot

The impact of the increased fuel prices is obvious only during peak load times when oil or gas plants are needed. During this period, the marginal costs are slightly higher than those of base model $(7.4 \%$ on average from $41.32 € / \mathrm{MWh}$ in the base model to $44.66 € / \mathrm{MWh}$ in the model with increased fuel prices). The impact of reduced plants' availability is quite similar. There is a no significant difference during off-peak and mid-load periods between the sensitivity testing case and the base model. This is because during off-peak times, the remaining capacity is still sufficient to keep a moderate price level even though the available capacity has been reduced. The impact is more obvious during peak times but the difference is rather small.

\subsection{Discussion}

Even though the robustness tests confirm the reliability of the results we obtained, it is important to underline that there might be always a significant margin between any simulated models and market reality. For example, the models considered in this paper are based on perfect knowledge, i.e., the bidders have always correct expectations about the market conditions. In reality, there might be asymmetric information; the bidders could have "wrong" expectations. Other two important weaknesses of any direct simulation of marginal costs are the lack of information on the real availability of power plants and the unlikelihood of estimating the opportunity costs. Indeed, the availability rate of a power plant can vary hourly due to the conditions on temperatures, the water levels or plant outages. This was not taken into account in the model. Estimating opportunity costs are even more challenging. Hydropower plants have variable costs at zero but opportunity costs might be high because of their dynamic flexibility. Indeed, hydroelectric plants are actually the only cheap way to "store" electricity thanks to its water storage system (pump storage facilities) ${ }^{8}$. So the opportunity cost of producing any MWh of electricity by a hydroelectric plant during the off-peak times, for example, is the revenue that the

8 This is not really a form of storage of power: the water must pass through a turbine-generator to create electricity. So in many ways it is the same as having a coal pile except that the hydro responds much faster. 
firms could have gained if they stored water and used this to produce electricity during peak times. We did not explicitly take this into account in the model. We are fully aware of these limitations while interpreting the results.

In order to understand better the implication of the high observed market prices and potential markups, it is essential to emphasize that the year 2011 marked an energy policy shift in Germany following the nuclear accident in Fukushima, which leads to the immediate shut-down of eight nuclear power plants. At the same time there was a strong expansion of volatile renewable power plant capacity, which has to be purchased and transmitted with priority by the grid operators, and is priced at zero but remunerated with fixed feed-in tariffs pursuant Renewable Energy Sources Act (EEG). These two factors have led to a noticeable decrease in the capacities of the four leading network operators RWE, E.ON, Vattenfall and EnBW according to the Electricity and Gas Monitoring Report 2012 of BNetzA and German Cartel Office. Prices during this period were higher on average and much more volatile than in previous years. This made market power more likely to be abused because firms would take this into account when they are maximizing their profits.

On the one hand, the shutdown of eight nuclear power plants after March 2011 necessitated mid and peak plants like lignite or coal $^{9}$ to substitute a part of the withdrawn nuclear capacity. However, this was not supposed to lead to significant increases of prices because expensive gas and oil were not much mobilized during this period. Furthermore, a great part of the nuclear shutdown had been replaced by the nuclear capacity imported from neighboring countries like France. On the other hand, the massively expanding highly-subsidised renewables had led to significant decreases of prices. This impact, known as merit-order effect, has been quantified in a number of papers, for instance, Sensfuss, Ragwitz and Genoese [2008], Weigt [2009], Gelabert, Labandeira and Linares [2011], Wurzburg, Labandeira and Linares [2013], Cludius, Hermann, Matthes and Graichen [2014], Ketterer [2014]. Yet, the observed EPEX spot prices have exhibited high levels in 2011 (figure 2). The doubt on the possibility of market power abuse could thus be justified.

Last but not least, the model carried out in this chapter does not explicitly take into account the role of constraints and congestions on the transmission grids. This refers to both internal congestions (Germany's South - North) and cross-border congestions. Indeed, when congestions bind at a given point of the network, no electricity can be imported/exported in/to the local area where there is congestion. As consequences, prices should increase. Ignoring this factor could possibly lead to under-estimation of actual marginal costs. However, integrating network to our model context is very complex because it requires the data information on each lines and nodes of the network.

If we allow a margin of up to $10 \%$ for estimation errors or for the omission of several factors as described above, the mark-ups level becomes less significant but is still obvious. On average, the

\footnotetext{
${ }^{9}$ Due to the high gas prices and relatively low coal price in Europe, many of gas plants have been shut down.
} 
markup of around $7 \%$ raises the question about whether missing data and model simplifications are solely responsible for this divergence.

\section{Conclusion}

Energy market in Germany has undergone fundamental changes in 2011. Following the Fukushima nuclear accident in March 2011, Germany decided to accelerate the phase-out of nuclear power by 2022 starting with the immediate closure of the eight oldest plants. This decision resulted in the adoption of a set of policy instruments commonly known as the Energiewende. Prices in wholesale market in this year have been observed to be at the highest level on average during the period 2009-2013. Studying market power for German wholesale electricity market in 2011 is thus highly relevant for both academics and regulators.

Following the method of linear programming as commonly used in literature, we simulate a competitive benchmark for German wholesale market in which all demand is cleared via a single market process. Marginal costs and market clearing prices under the hypothesis of perfect competition are estimated via an optimization program in which costs are minimized, subject to several technical constraints and energy balance. This competitive benchmark is then compared with EPEX spot prices. On the basis of the difference between modeled marginal costs and observed market prices, we estimate the price-cost markups, or the Lerner Indexes across hours.

The model-based results suggest that on average the EPEX prices are about 17\% higher than the simulated competitive benchmark. The divergence is mostly observed during the peak time, up to $20 \%$ in the morning and evening peak hours when demand is high. Even if we allow for $10 \%$ of missing information or model simplification, the price-cost markups are still significant. We verify the robustness of the results by conducting two sensitivity tests: first, we increase the fuel prices for oil and gas by $10 \%$, and second, we reduce the plant availability. In both sensitivity tests, the off-peak prices are almost unaffected and the peak prices are slightly higher. The results stay robust.

While we acknowledge the common limitations of this modelling approach, the large number of significant price differentials could indicate that the market is not yet sufficiently competitive to overcome market abuse particularly in peak times. 


\section{References}

Atkins, R and A Taylor, Germany shows the way for Europe, Financial Times, 1999, 21.

Benhmad, François and Jacques Perçebois, Les distorsions induites par les énergies intermittentes sur le marché spot de l'électricité, Economies et Sociétés, 2013, 2, 275-297.

BNetzA, List of Power Plants, Bundesnetzagentur (BNetzA), Accessed 29 October 2014.

Bower, John, Derek W Bunn, and Claus Wattendrup, A model-based analysis of strategic consolidation in the German electricity industry, Energy Policy, 2001, 29 (12), 987- 1005.

Borenstein, S. (2000). Understanding competitive pricing and market power in wholesale electricity markets. The Electricity Journal, 13(6), 49-57.

Competition, Directorate-General, DG Competition report on energy sector inquiry, SEC (2006), $2007,1724$.

der Kohlenwirtschaft, Statistik, Entwicklung ausgewa hiler Energiepreise, Accessed 2013, 2013.

FNA and FCO, Monitoring Report 2012, Developments of the Electricity and Gas Markets in Germany, Technical Report 2013.

Harvey, Scott and William Hogan, Market power and market simulations, Retrieved May, 2002, 4, 2007.

Janssen, Matthias and Magnus Wobben, Electricity pricing and market powerevidence from Germany, European Transactions on Electrical Power, 2009, 19 (4), 591-611.

Kunz, Friedrich and Alexander Zerrahn, The Benefit of Coordinating Congestion Management in Germany, Technical Report 2013.

Lang, Christoph and H. Schwarz, Rise in German Wholesale Electricity Prices: Funda- mental Factors, Exercise of Market Power, or Both?, IWE Working Paper Nr. 02, 2006.

Möst, Dominik and Massimo Genoese, Market power in the German wholesale electricity market, The Journal of Energy Markets, 2009, 2 (2), 47-74.

Müsgens, Felix, Quantifying market power in the German wholesale electricity market using a dynamic multi-regional dispatch model, The Journal of Industrial Economics, 2006, 54 (4), 471-498.

OECD/IEA, Energy Policies of IEA Countries: Germany 2013, Technical Report 2013. 26

Meritet, Sophie and Pham, Thao, Market power in power markets: The case of French electricity wholesale market, Energy Studies Reviews, 2015, 21 (2) 
Schill, Wolf-Peter and Claudia Kemfert, Modeling strategic electricity storage: the case of pumped hydro storage in Germany, Energy Journal-Cleveland, 2011, 32 (3), 59.

Schröder, Andreas, Friedrich Kunz, Jan Meiss, Roman Mendelevitch, and Christian Von Hirschhausen, Current and prospective costs of electricity generation until 2050, German Institute for Economic Research, DIW Berlin, 2013, 12.

Twomey, P., Green, R. J., Neuhoff, K., \& Newbery, D. (2006). A review of the monitoring of market power the possible roles of tsos in monitoring for market power issues in congested transmission systems.

Weigt, Hannes and Christian Von Hirschhausen, Price formation and market power in the German wholesale electricity market in 2006, Energy policy, 2008, 36 (11), 4227- 4234. 


\section{Appendix}

Figure 7: Simulated annual elecitricty production for different plant types - 2011

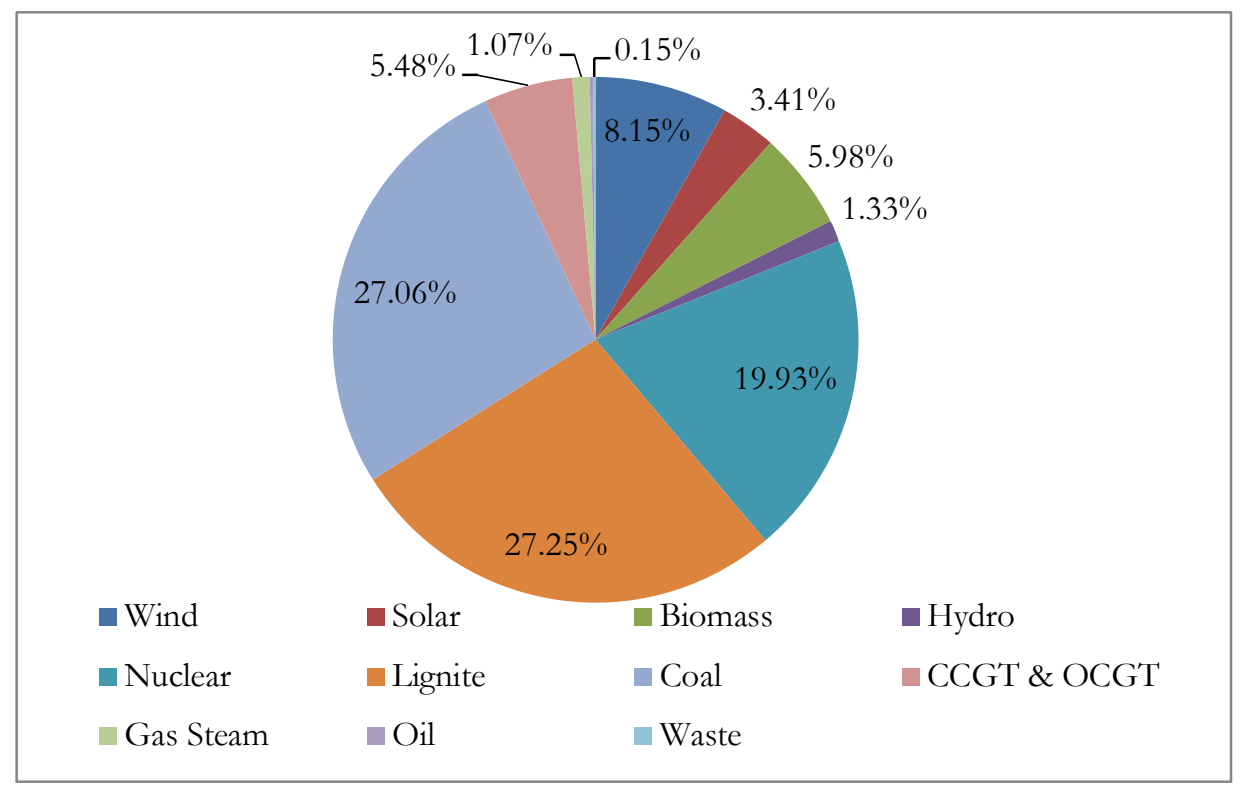

Source: Own calculations and EPEX Spot

Figure 8: Simulated hourly dispatched thermal output and renewables' capacity

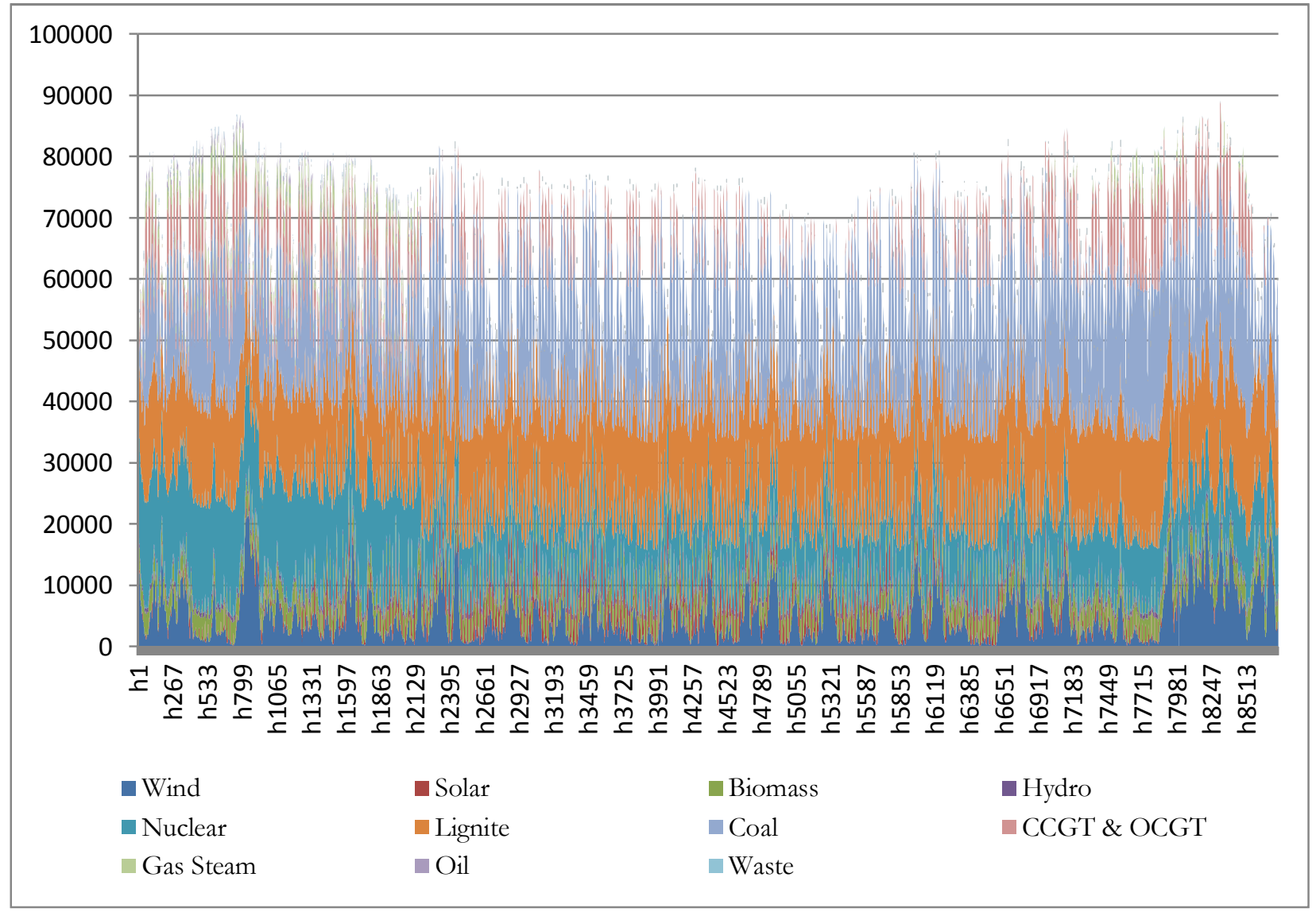

Source: Own calculations and EPEX Spot 
Figure 9: Simulated merit order - 2011

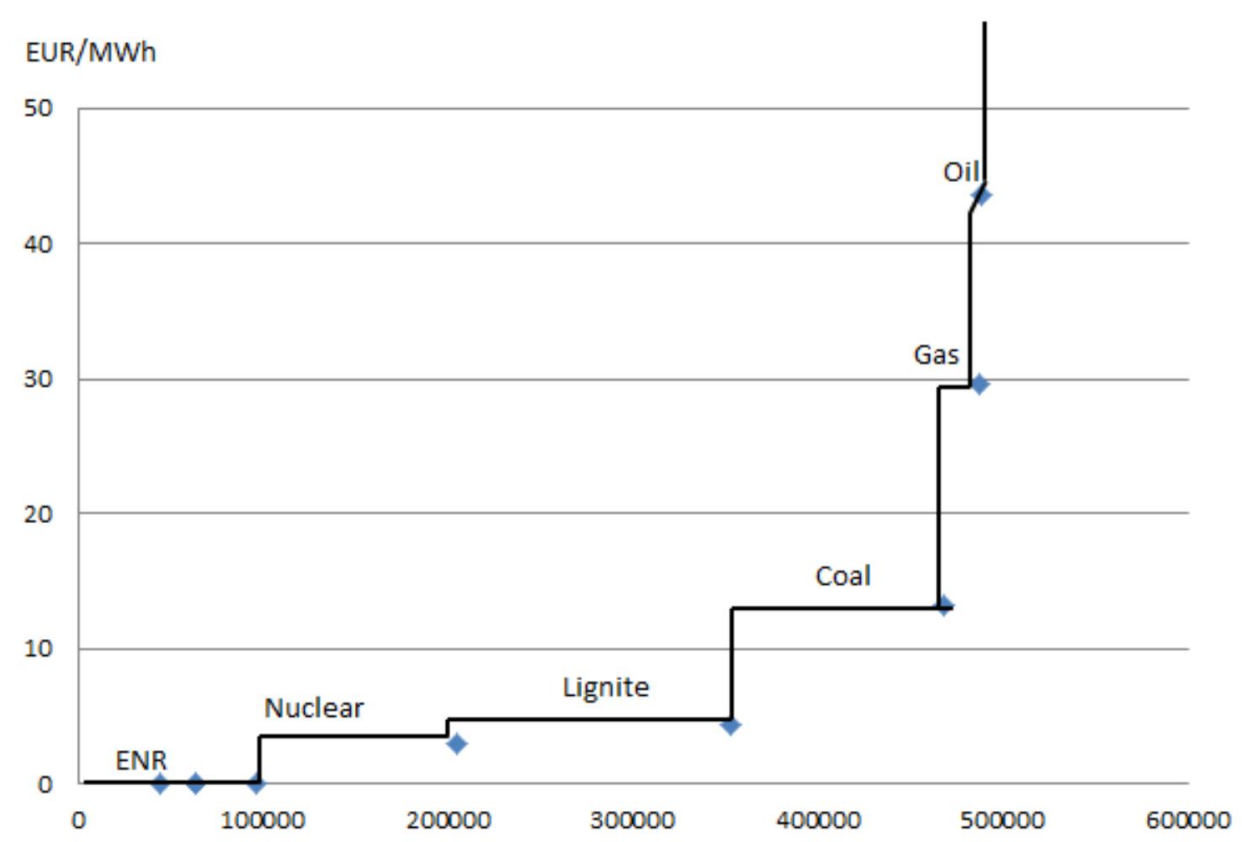

Source: Own calculations and EPEX Spot

The marginal generation costs in the vertical axe do not include the operating costs as well as the costs for CO2 emissions. The generation outputs from renewables are supposed to have zero cost and to be automatically dispatched. 